\title{
The Effects of a Peer-Delivered Writing Planning Intervention for Struggling Fifth Graders
}

\author{
Matthias Grünke, ${ }^{1, *}$ \\ ${ }^{1}$ Department of Special Education \& Rehabilitation, University of Cologne, Germany \\ *Correspondence: Matthias Grünke, Department of Special Education \& Rehabilitation, University of Cologne, \\ Klosterstr. 79b, 50931 Cologne, Germany. Tel: 49-221-470-5547. E-mail: matthias.gruenke@uni-koeln.de
}

Received: November 22, 2018

Accepted: December 15, 2018 Online Published: December 20, 2018

doi:10.5430/wje.v8n6p157

URL: https://doi.org/10.5430/wje.v8n6p157

\begin{abstract}
Good writing skills are vital to success in school and, later, in the workplace. However, many elementary and secondary students fail to invest sufficient time and effort in planning what they want to write and, consequently, produce texts of inferior quality. One approach to help struggling children and adolescents acquire effective writing planning abilities is called story-mapping. In this single-case study, the story-mapping method was applied in a peer-tutorial setting to help three low-achieving fifth graders brainstorm their ideas and organize their thoughts prior to composing a narrative. During the course of the intervention, all tutees were able to significantly increase the number of words that they generated to write their texts. The study demonstrated that peer-tutoring can be successfully implemented to combat deficiencies in writing planning skills and help struggling students to improve their performance in a meaningful way.
\end{abstract}

Keywords: writing instruction, peer-tutoring, single-case research, learning problems

\section{Introduction}

Many educators feel overburdened when faced with the challenge of teaching their students to express themselves in writing (Troia \& Graham, 2003). The process of transferring ideas or information into text is extremely complex. Writers need to demonstrate automaticity in basic spelling and handwriting skills, keep their potential readership in mind, be creative, activate their background knowledge about a given subject, produce cohesive trains of thought, be aware of the purpose of their activities, and much more (Santangelo, 2014). Under the stress of a classroom situation, teachers all too often do not find the time to instruct students how to master all the steps necessary to become proficient writers (Gillespie Rouse \& Kiuhara, 2017). According to the National Center of Educational Statistics (2011), written language skills remain the single most demanding academic task to teach successfully. As a consequence of not meeting this challenge adequately, many students fail in basic text production tasks (Katusic, Colligan, Weaver, \& Barbaresi, 2009). In fact, the National Center of Educational Statistics (2011) has discovered that at least one-third of all high school students in the U.S. intending to move on to higher education do not meet the basic readiness requirements for college composition courses.

Being part of a population of children and adolescents struggling with using written language to express communicative intents comes with many detriments. Writing is one of the most powerful ways to demonstrate knowledge. Students who are not able to meet minimal standards in this respect will face significant barriers in education, the work force, and private life (Graham, 2006; Grünke \& Leonard Zabel, 2015).

A promising starting point for supporting students who have trouble with text production would be to help them improve the relevant subskills with which they have the greatest difficulty, and which can easily be influenced by sound interventions taught by peers instead of by professionals. Given a means of providing assistance in the classroom in this way, we would possess an urgently needed tool to reverse the widespread declining spiral of failure in writing. Research has shown that the text production activities of struggling students are characterized by a lack of time and effort invested in prewriting endeavors. This includes (1) developing, prioritizing, and modifying goals, (2) generating possible ideas, and (3) selecting and organizing the thoughts that they consider meaningful (Graham, Collins, \& Rigby-Wills, 2017; MacArthur \& Graham, 1987; Rodríguez, Grünke, González-Castro, García, \& 
Álvarez-García, 2015; Santangelo, 2014). Fittingly, in their meta-analysis, Rogers and Graham (2008) were able to determine that efforts to teach prewriting skills by generating ideas through graphic organizers (including story maps and outlines) were relatively effective in enhancing the quality of stories composed by elementary and secondary students. In their research synthesis, De Smedt and Van Keer (2014) concluded that the most effective way of instructing children to produce text is to combine strategy instruction with collaborative writing.

Graphic organizers are tools designed to visualize and organize information. Story maps are specific kinds of graphic organizers that outline the important components of a story (e.g. settings, characters, and events) through uniquely arranged blanks. They are intended to provide visual reminders of central elements of narratives while offering a space in which writers can jot down their ideas (Li, 2007).

A database query in Academic Search Complete, ERIC, MEDLINE, PsycINFO, and TOC Premier, using the algorithm "collaborative learning OR collaborative writing OR peer-tutoring OR peer learning" AND "graphic organizer OR story mapping OR story maps" AND "written OR writing OR text production" yielded five hits in academic journals. Two of the identified articles actually described empirical studies on teaching composition skills to struggling writers through peer-tutoring: Grünke, Janning, and Sperling (2016) and Grünke, Wilbert, Tsiriotakis, and Agirregoikoa (2017). In both cases, the authors used graphic organizers as a means to enable tutors to teach story-writing skills to low-achieving third- and fourth-grade tutees. The results are very promising. In both instances, the treatment was highly effective in improving not only the length, but also the quality of the narratives that the tutees composed.

However, the research base on the benefits of using story maps to teach prewriting skills to struggling learners through peer-tutoring is rather limited, especially in the case of secondary students who are not proficient in composing simple stories. The purpose of this study was, therefore, to employ story mapping to teach text-planning skills to three children who had just entered secondary education by using classmates as instructors. It was expected that they would produce increasingly longer narratives over the course of the intervention.

\section{Method}

\subsection{Participants}

Three tutees and three tutors served as participants in this study. All of them attended a fifth grade class in a comprehensive secondary school ("Gesamtschule") in a major city in Northrhine-Westfalia (Germany). The three tutees were Adriana, Badu, and Cavit; the three tutors were Anna (who worked with Adriana), Bahar (who worked with Badu), and Celile (who worked with Cavit) (names changed for anonymity).

Adriana (female) was born in Germany after her parents emigrated from Italy. She was eleven years old at the time of the study. Everyone in her family spoke Italian at home. Badu (male) was ten years of age at the start of the experiment. He was also born in Germany. His father was a citizen of Togo, but his mother did not have an immigrant background. Even though Badu's father had only fragmentary German language skills, he and everyone else at home used German as their mode of communication. Cavit (male) was ten years old when he participated in this research. He and his parents were all born in Germany, but everyone spoke Turkish at his home. Anna (female) was ten years old and did not have an immigrant background. Bahar and Celile were both female, both were eleven years of age, both were born in Germany, both had Turkish parents, and both spoke Turkish at home. None of the participants was ever diagnosed with any kind of learning disability.

Assignment to the role of tutee or tutor was based on students' performance in the Duisburg Language Proficiency Test (DLPT, Pietsch \& Theinissen, 2007). Tutees had to score below average in the areas of grammar, syntax, and vocabulary. However, they had to demonstrate spelling skills above the 30th percentile. Tutors had to score at least in the average range in all of the aforementioned areas. Out of all 25 students that participated in an initial investigation with the DLPT, the three that produced the fewest words in response to a writing prompt were designated as tutees, and the three that produced the most words were selected as tutors. The classroom teacher paired the teams based on her appraisal of who got along best with whom.

\subsection{Design}

A multiple baseline design across subjects (AB) (Ledford \& Gast, 2018) was employed to evaluate the effectiveness of the procedure. To increase the internal validity of the study (see Dugard, File, \& Todman, 2012; Tate et al., 2016), the beginning and the end of the intervention were determined randomly for each case within the constraint that the A-phase had to consist of at least five and the B-phase of at least three measurements. Thus, the intervention could have started at any time between the 6th and the 11th probe. A random drawing of all six possible options for each 
tutee resulted in an arrangement whereby the treatment began for Adriana after the 6th, for Badu after the 9th, and for Cavit after the 8th baseline measurement.

\subsection{Depedent Variable}

The tutees' skill levels were assessed by asking them to produce a story in response to randomly chosen prompts taken from Sacher (2012). It was ensured that the same topic was never used twice. No time limits were imposed. Performance was determined by counting the number of recognizable words regardless of spelling or context, excluding digits. This index is commonly known as "total words written" (TWW). Amato and Watkins (2001) posited that TWW is the strongest measure correlated with a variety of different writing criteria. The study extended over 13 consecutive school days. On each of these days, the performance of the tutees was captured. Inter-rater reliability was ensured by having two independent reviewers count the number of words in each story after the experiment ended. In accordance with the fact that TWW is a markedly objective mode of measuring writing performance (Hosp, Hosp \& Howell, 2016), agreement between the two raters reached $100 \%$.

\subsection{Procedures}

In preparation for the intervention, a 26-year-old female graduate student of special education instructed the three tutors in how to perform the treatment during three 45-minute briefing sessions. Over the course of the study, the three teams were taken to a resource room in their school each day during third period (9:50 to 10:35 a.m.). They were seated as far apart as possible. Because the room was also occupied by other students engaging in different kinds of work, the tutees did not seem to pick up on what the other teams were doing. Prior to the start of the training, tutors and tutees engaged in educational card games, presenting them with different brain teasers. Each baseline and intervention session lasted 25 minutes.

The treatment began with three daily instructional lessons. All lessons started with the tutors presenting the tutees with a randomly selected story prompt from Sacher (2012). Different topics were deployed for measuring TWW and for teaching the use of story maps. Following prompt selection, the tutors generated ideas on what they could write about while thinking aloud and noted their thoughts in suitable blanks on a pre-prepared story map. The story map templates had been printed on DIN A-4 paper and entailed three fields (see Figure 1).

\section{My Story Map}

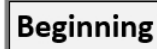

Figure 1. Story Map Template 
The tutees spent the remaining time of the first three lessons trying to imitate what they had observed the tutors doing with different prompts. Meanwhile, the tutors provided any support necessary to assist the tutees in brainstorming ideas and in writing them in the respective blanks. During the rest of the sessions, each team wrote stories collaboratively without pre-prepared story maps. However, the tutors had previously been briefed to draw their own graphic organizers on notepaper that had been provided for them. The tutors encouraged the tutees to perform the task more and more independently until their guidance faded out completely. The university student used a checklist as she monitored the faithful delivery of all training sessions and provided assistance as necessary.

At the end of each baseline and intervention session, the tutors were permitted to return to their classes, while the university student assessed the performance of the tutees (see above). The tutees had as much notepaper at their disposal as they needed. Even though they were not instructed to do so, they all began to draw story maps while planning their texts as soon as they had participated in their first training session.

\section{Results}

Figure 2 depicts TWW for Adriana. Baseline data was relatively stable (60, 47, 41, 52, 48, 31). At the onset of treatment, performance increased continuously $(89,96,136,209,330,341,400)$ until the participant achieved an impressive high. Common effect size measures for single-case research - percentage of non-overlapping data (PND), percentage of all non-overlapping data (PAND), and percentage of data exceeding the median trend (PEM-T) (Lenz, 2013) - all reached their highest possible score (100). To determine whether Adriana had a statistically significant treatment effect, a weighted Tau-U (A vs. B + trend B - trend A) was calculated using an online tool by Vannest, Parker, and Gonen (2011). This method integrates both trend and non-overlap with values ranging from -1 to 1 (Parker, Vannest, Davis, \& Sauber, 2011). The analysis yielded an effects size of $0.90(\mathrm{p}<.001)$.

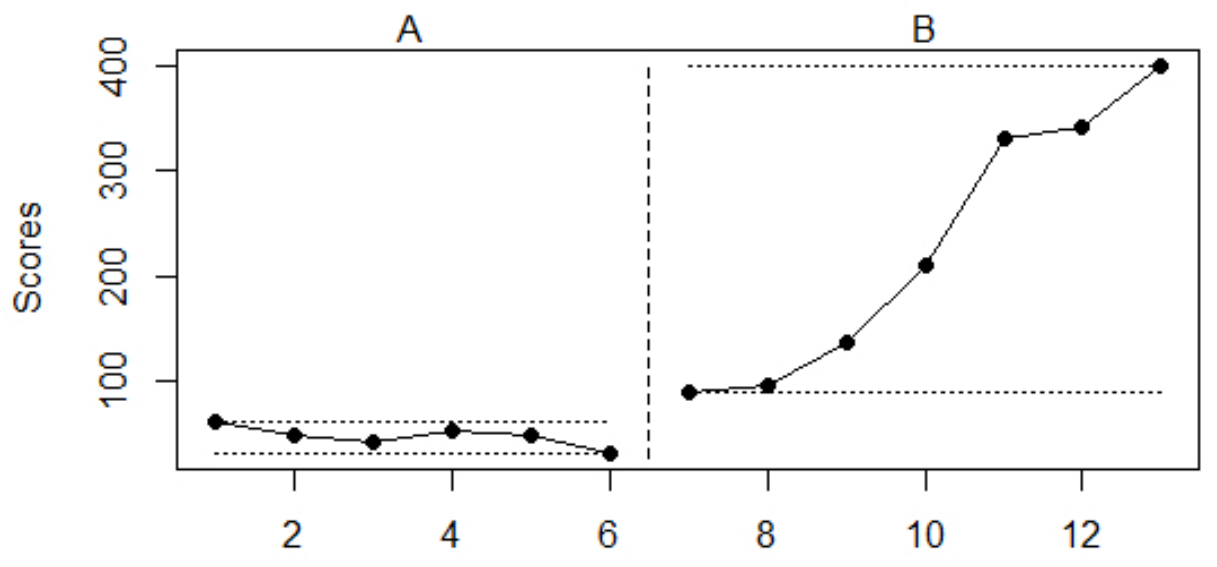

Figure 2. TWW of Adriana

The data for Badu are presented in Figure 3. His baseline scores $(64,42,52,48,36,27,41,59,17)$ are less steady than Adriana's or Cavit's. Whereas the standard deviations of the data points prior to the treatment equaled 9.85 and 10.53 in the cases of Adriana and Cavit, respectively, Badu's value was 14.95. As soon as the intervention started, his performance rose considerably $(87,100,105,101)$. However, due to a slight drop in TWW at the last measurement, his data curve did not show a perfect increase from prompt to prompt. PND, PAND, and PEM-T all equaled 100. Finally, Badu reached a weighted Tau-U of $0.72(\mathrm{p}<.001)$. 


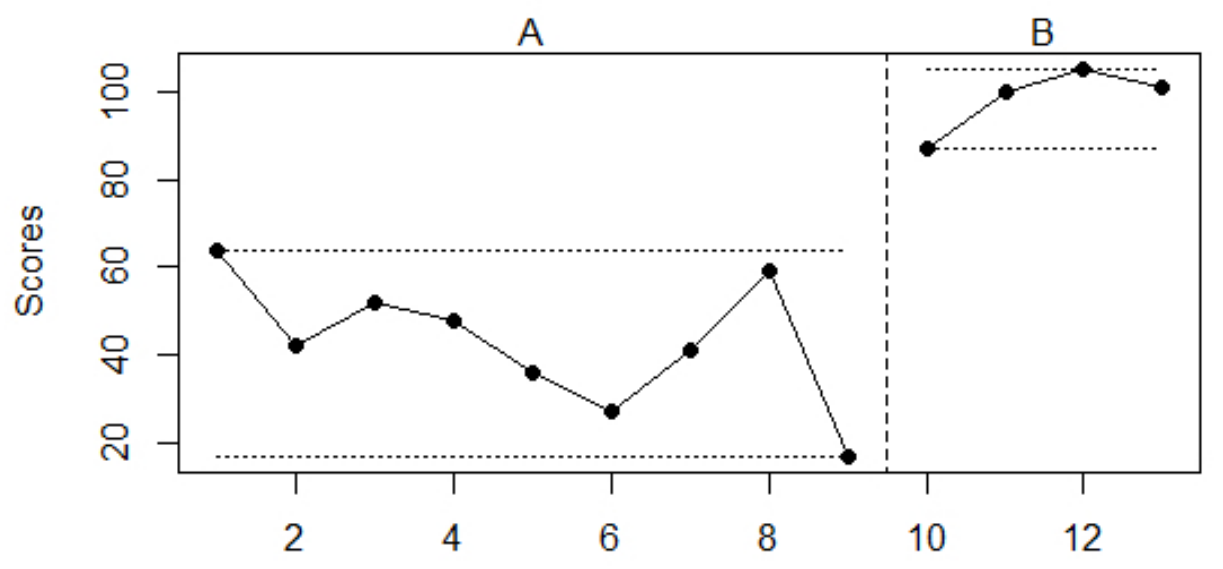

Figure 3. TWW of Badu

Figure 4 shows Cavit's TWW during the measurements in both phases. His baseline scores $(58,49,45,28,32,47,40$, 30) can be considered comparatively stable. The beginning of the treatment elicited a blatant and then continuous rise in performance $(100,112,121,168,305)$. Again, all effect size indices (PND, PAND, and PEM-T) reached the peak value (100). The weighted Tau-U for Cavit equaled $0.82(\mathrm{p}<.001)$.

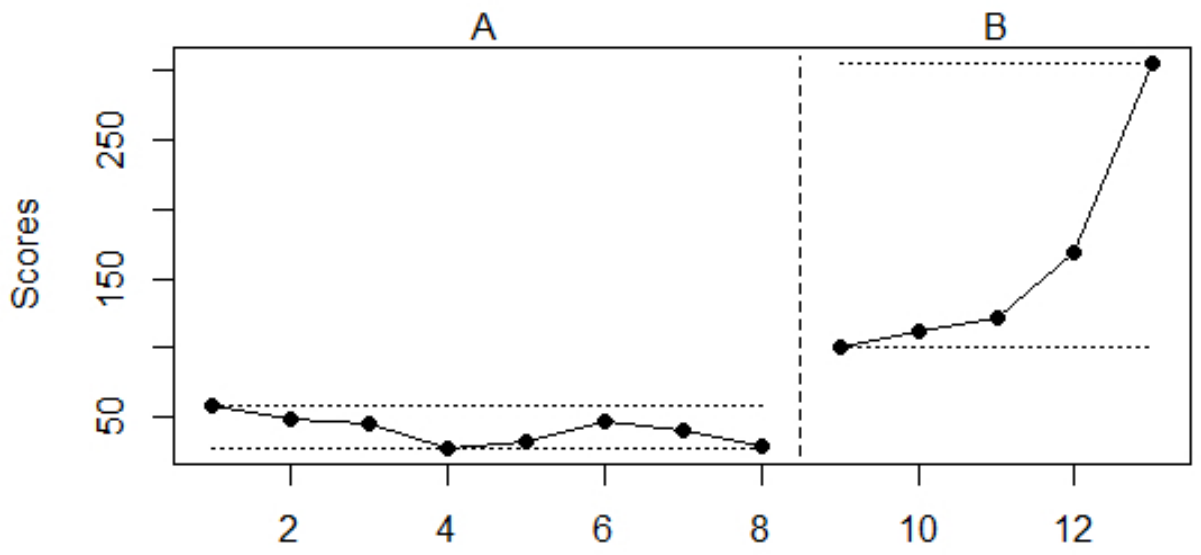

Figure 4. TWW of Cavit

Aggregating all three cases into one to determine a combined weighted Tau- $U$ for all participants resulted in a value of 0.81 ( $\mathrm{p}$ <001). According to tentative benchmarks for interpreting Tau-U indices (Parker and Vannest 2009; Rakap 2015), this suggested a medium overall intervention effect.

\section{Discussion}

In this multiple-baseline across-individuals study, it was documented that struggling fifth-grade writers who were trained by high performing classmates to use story maps to plan narratives composed progressively longer texts over the course of the intervention. Visual inspection and calculation of different effect sizes all spoke to the supposition that the treatment was highly effective in supporting learners who had trouble conveying thoughts in written language. An analysis of the data using weighted Tau- $U$ indices revealed that the differences in trend and non-overlap between phases could not be accounted for by chance with a probability of less than $0.1 \%$. Anecdotal reports by the university student and informal feedback from the four tutees suggested that the training was well received and fun for the participants. Adriana, Badu, and Cavit appeared to be proud of their achievements. In addition, they all stated that they had always detested writing, but that the peer-tutorial setting and the instruction on how to use story maps made them enjoy it. 
These findings are consistent with those from previous studies (Grünke, Janning, \& Sperling, 2016; Grünke, Wilbert, Tsiriotakis, \& Agirregoikoa, 2017). Serendipitously, the present experiment was able to document for the first time that an intervention as described above can be effective not only with elementary students, but also with young secondary students who struggle with text production.

Despite these promising results, the current investigation should be interpreted in light of a number of limitations. To begin, no follow-up data were collected to monitor how well the tutees generalized their skills into daily work. Additionally, only the number of TWW was considered to evaluate the usefulness of the training. However, other quantitative and qualitative modes of measurement could have shed more light on how the treatment affected the tutees. Even though TWW usually correlates very highly with different qualitative ways of assessment (Grünke, Büyüknarci, Wilbert, \& Breuer, 2015), it would have been helpful to involve diagnostic instruments to capture the coherence, the cohesiveness, the style and the tone, and other qualitative criteria that are used to assess narratives. Furthermore, the evaluation only focused on the tutees, not on the tutors. It remains to be determined whether the students giving the instruction also benefited from the format of the intervention. Finally, to better appraise the benefits of teaching story mapping through peer-tutoring, future research should be carried out with larger number of participants and across a wider range of skills.

Regardless of any limitations that this research encountered, one of the greatest strengths of the intervention evaluated in this study was its high practicability. The peer-tutorial method was effective and easy to implement under everyday conditions in school. As mentioned earlier, many students demonstrate very weak text production skills and dislike writing. This experiment indicated that thus situation can be changed with relatively little effort. The materials used in this study were cost-efficient (compared to expensive workbooks or commercial training programs). In addition, teachers did not have to continuously attend to the needs of individual struggling students to help them learn how to compose longer stories and enjoy the writing process. Peers were also able to model, lead, and motivate low-achieving classmates and provide effective scaffolding on their way to becoming more proficient writers.

\section{Conclusion}

In conclusion, this study adds to the accumulating body of evidence on how to support students struggling with text production through peer-tutoring. Intervention researchers should feel encouraged to collect more data on how systems of instructions in which learners help each other and learn by teaching (Goodlad \& Hirst, 1989) could contribute to better support young people in danger of being socially excluded due to poor writing skills.

\section{References}

Amato, J. M., \& Watkins, M. W. (2011). The predictive validity of CBM writing indices for eighth grade students. The Journal of Special Education, 44, 195-204. https://doi.org/10.1177/0022466909333516

De Smedt, F., \& Van Keer, H. (2014). A research synthesis on effective writing instruction in primary education. Procedia: Social and Behavioral Sciences, 112, 693-701. https://doi.org/10.1016/j.sbspro.2014.01.1219

Dugard, P., File, P., \& Todman, J. (2012). Single-case and small-n experimental designs: A practical guide to randomization tests. New York, NY: Routledge. https://doi.org/10.4324/9780203180938

Gillespie Rouse, A., \& Kiuhara, S. A. (2017). SRSD in writing and professional development for teachers. Learning Disabilities Research \& Practice, 32, 180-188. https://doi.org/10.1111/ldrp.12140

Goodlad, S., \& Hirst, B. (1989). Peer-tutoring: A guide to learning by teaching. New York, NY: Nichols.

Graham, S. (2006). Writing. In P. Alexander \& P. Winne (Eds.), Handbook of educational psychology (2nd ed., pp. 457-478). Mahwah, NJ: Lawrence Erlbaum.

Graham, S., Collins, A. A., \& Rigby-Wills, H. (2017). Writing characteristics of students with learning disabilities and typically achieving peers: A meta-analysis. Exceptional Children, 83, 199-218. https://doi.org/10.1177/0014402916664070

Grünke, M., Büyüknarci, Ö., Wilbert, J., \& Breuer, E. (2015). To what extent do certain characteristics of a child's written story influence the way it is rated? Insights into features necessary for supporting struggling writers. Insights into Learning Disabilities, 12, 163-177.

Grünke, M., Janning, A. M., \& Sperling, M. (2016). The effects of a peer-tutoring intervention on the text production 
of students with learning and speech problems: A case report. Learning Disabilities: A Contemporary Journal, $14,225-235$.

Grünke, M., \& Leonard Zabel, A.-M. (2015). How to support struggling writers: What the research stipulates. International Journal of Special Education, 30, 137-150.

Grünke, M., Wilbert, J., Tsiriotakis, I. K., \& Agirregoikoa, A. L. (2017). Improving the length and quality of texts written by fourth graders with learning disabilities through a peer-tutoring graphic organizing strategy. Insights into Learning Disabilities, 14, 167-188.

Hosp, M. K., Hosp, J. L., \& Howell, K. W. (2016). The ABCs of CBM: A practical guide to curriculum-based measurement. New York, NY: Guilford.

Katusic, S. K., Colligan, R. C., Weaver, A. L., \& Barbaresi, W. J. (2009). The forgotten learning disability: Epidemiology of written-language disorder in a population-based birth cohort (1976-1982). Paediatrics, 123, 1306-1313. https://doi.org/10.1542/peds.2008-2098

Ledford, J. R., \& Gast, D. L. (2018). Single case research methodology: Applications in special education and behavioral sciences. New York, NY: Routledge. https://doi.org/10.4324/9781315150666

Lenz, A. S. (2013). Calculating effect size in single-case research: A comparison of non-overlap methods. Measurement and Evaluation in Counselling and Development, 46, 64-73. https://doi.org/10.1177/0748175612456401

Li, D. (2007). Story mapping and its effects on writing fluency and word diversity of students with learning disabilities. Learning Disabilities: A Contemporary Journal, 5, 77-93.

MacArthur, C. A., \& Graham, S. (1987). Learning disabled students' composing under three methods of text production: Handwriting, word processing, and dictation. Journal of Special Education, 21, 22-42. https://doi.org/10.1177/002246698702100304

National Center for Education Statistics (2012). The nation's report card: Writing 2011 (NCES 2012-470). Washington, D.C.: Institute of Education Sciences, U.S. Department of Education.

Parker, R. I., \& Vannest, K. J. (2009). An improved effect size for single case research: Non-overlap of all pairs (NAP). Behavior Therapy, 40, 357-367. https://doi.org/10.1016/j.beth.2008.10.006

Parker, R. I., Vannest, K. J., Davis, J. L., \& Sauber, S. B. (2011). Combining non-overlap and trend for single-case research: Tau-U. Behavior Therapy, 42, 284-299. https://doi.org/10.1016/j.beth.2010.08.006

Pietsch, H., \& Theunissen, U. (2007). Duisburg Language Proficiency Test (DLPT). Duisburg, Germany: Gesamtschule Duisburg-Meiderich.

Rakap, S. (2015). Effect sizes as result interpretation aids in single-subject experimental research: Description and application of four non-overlap methods. British Journal of Special Education, 42, 11-33. https://doi.org/10.1111/1467-8578.12091

Rodríguez, C., Grünke, M., González-Castro, P., García, T., \& Álvarez-García, D. (2015). How do students with Attention Deficit/Hyperactivity Disorders and Writing Learning Disabilities differ from their non-labeled peers in the ability to compose texts? Learning Disabilities: A Contemporary Journal, 13, 157-175.

Rogers, L. A., \& Graham, S. (2008). A meta-analysis of single subject design writing intervention research. Journal of Educational Psychology, 100, 879-906. https://doi.org/10.1037/0022-0663.100.4.879

Sacher, J. (2012). The amazing story generator: Creates thousands of writing prompts. San Francisco, CA: Chronicle Books.

Santangelo, T. (2014). Why is writing so difficult for students with learning disabilities? A narrative review to inform the design of effective instruction. Learning Disabilities: A Contemporary Journal, 12, 5-20.

Tate, R. L., Perdices, M., Rosenkoetter, U., Shadish, W., Vohra, S., Barlow, D. H., . . . Wilson, B. (2016). The single-case reporting guideline in behavioural interventions (SCRIBE) 2016 statement. Archives of Scientific Psychology, 4, 1-9. https://doi.org/10.2522/ptj.2016.96.7.e1

Troia, G. A., \& Graham, S. (2003). Effective writing instruction across the grades: What every educational consultant should know. Journal of Educational and Psychological Consultation, 14, 75-89. https://doi.org/10.1207/S1532768XJEPC1401_04 
Vannest, K. J., Parker, R. I., \& Gonen, O. (2011). Single case research: Web based calculators for SCR analysis (Version 1.0) [Webbasedapplication]. College Station, TX: Texas A\&M University. 